\title{
INTERÉS ASEGURABLE EN LOS CONTRATOS DE LEASING."
}

\author{
LÍNEA JURISPRUDENCIAL
}

\author{
LEASE INSURANCE.
}

A LINE OF JURISPRUDENCE

\author{
OSCAR EDUARDO SALAMANCA IBARRA** \\ Fecha de recepción: 30 de septiembre 2019 \\ Fecha de aceptación: 01 de febrero 2020 \\ Disponible en línea: 30 de diciembre 2020
}

Para citar este artículo/To cite this article

Salamanca Ibarra, Oscar Eduardo, Interes asegurable en los contratos de leasing. Línea jurisprudencial, 53 Rev.Ibero-Latinoam.Seguros, 355-376 (2020). https://doi.org/10.11144/ Javeriana.ris53.iacl

doi:10.11144/Javeriana.ris53.iacl

\footnotetext{
Trabajo presentado para optar el título de Especialista en Derecho de Seguros de la Facultad de Ciencias Jurídicas de La Pontificia Universidad Javeriana.

** Especialista en Derecho de seguros de la Pontificia Universidad Javeriana.
} 


\section{RESUMEN}

El presente trabajo tiene por finalidad efectuar un análisis de las sentencias propuestas de forma que se puedan evidenciar los criterios aplicados por los jueces para la resolución de los casos. En este entendido, se efectuará una breve descripción de los hechos, se incluirá una breve reseña de los fallos de instancia y de los fundamentos adoptados en dichos fallos, se planteará un problema jurídico que a juicio del autor del presente trabajo se procuró resolver por parte de las Cortes y finalmente se hará un análisis crítico de la decisión adoptada conforme al problema jurídico planteado.

Las sentencias corresponden a casos en los que la controversia se deriva de la interpretación de contratos de leasing y el análisis de la existencia del interés asegurable sobre los bienes objeto de dichos contratos. Este análisis permitirá entender la posición jurisprudencial respecto al aseguramiento de los bienes objeto de este tipo de contratos, lo que a su vez permitirá comprender el alcance y la necesidad de propiciar un correcto aseguramiento de los diferentes intereses que pueden tener las partes, esto es el locatario y la compañía de leasing.

Palabras clave: Contrato de Leasing; compañía de leasing; análisis crítico 


\section{ABSTRACT}

This work presents an analysis of certain rulings showing the criteria implemented by judges to resolve certain particular cases. A brief description of the facts, a succinct review of the corresponding rulings and the grounds thereof as well as a legal problem that in the opinion of the author was sought to be solved by the Courts will be presented; finally, an analysis of the decision adopted as per the respective cited case will be conducted.

The rulings correspond to cases in which the controversy is derived from the interpretation of lease agreements and the analyses about whether the respective goods must be insured or not. This study allows the identification of the jurisprudence regarding the goods of this type of agreements, which in turn, allows to understand the scope and the need to appropriately include in an insurance policy the different interests the parties (lessor and lessee) may have.

Keywords: lease agreement, lease company, critical analysis

\section{SUMARIO}

1. Sentencia: Corte Suprema de Justicia -Sala de Casación Civil. Fecha: 23 de mayo de 2005. Expediente: 11001-3103-010-1996-2637-01 Magistrado ponente: Jaime Alberto Arrubla Paucar. A. Reseña. i. Hechos. ii. Problema(s) Jurídico(s). iii. Reseña de los fallos de instancia. iv. Fundamentos del fallo de segunda instancia. v. Recurso de Casación. vi. Consideraciones de la Corte. B. Evaluación crítica. 2. Sentencia: Corte Suprema de Justicia -Sala de Casación Civil. Fecha: 2 de diciembre de 2011. Expediente: 11001-3103-035-2000-0089901. Magistrado ponente: William Namén. A. Reseña. i. Hechos. ii. Problema(s) Jurídico(s). iii. Reseña de los fallos de instancia. iv. Fundamentos del fallo de segunda instancia. v. Recurso de Casación. Consideraciones de la Corte B. Evaluación crítica. 3. Sentencia: Consejo de Estado - Sección Tercera Subsección A. Fecha: 4 de noviembre de 2015. Expediente 25000-2326-000-199802485-01 (33571). Magistrado ponente: Hernán Andrade Rincón. A. Reseña. i. Hechos. ii. Problema(s) Jurídico(s). iii. Reseña de los fallos. iv. Fundamentos de la Sentencia Primera Instancia. v. Fundamentos de la Apelación. vi. Consideraciones del Consejo de Estado. B. Evaluación crítica. 4. Conclusiones generales 5. Referencias bibliográficas. 


\section{CORTE SUPREMA DE JUSTICIA -SALA DE CASACIÓN CIVIL.}

Fecha: 23 de mayo de 2005.

Expediente: 11001-3103-010-1996-2637-01.

Magistrado ponente: Jaime Alberto Arrubla Paucar.

\section{A. Reseña}

\section{i. Hechos}

- $\quad$ El 25 de agosto de 1992, entre el Señor Roberto Buitrago Dueñas, en calidad de locatario; y la sociedad Leasing Colmena S.A. Compañía de Financiamiento Comercial, en calidad de arrendadora, celebraron un contrato de leasing financiero respecto de una máquina retroexcavadora.

- $\quad$ La sociedad Leasing Colmena S.A., en calidad de tomador y ostentando las calidades de asegurado y beneficiario, contrató con la compañía Seguros Colmena S.A. un seguro contrato todo riesgo respecto de la retroexcavadora objeto del contrato de leasing. El demandante manifiesta que tal situación se produjo sin que la sociedad Leasing Colmena S.A., tuviera poder para suscribir dicho contrato.

- $\quad$ El 6 de julio de 1995 la máquina retroexcavadora fue hurtada.

- $\quad$ El 18 de octubre de 1995 la sociedad Leasing Colmena S.A., transfirió la propiedad sobre la misma al señor Roberto Buitrago Dueñas.

- Ya habiéndose presentado la reclamación del siniestro, el 24 de octubre de 1995 la compañía Seguros Colmena S.A., se dirige al señor Roberto Buitrago Dueñas y le comunica la decisión de objetar la reclamación.

- $\quad$ El locatario instauró la demanda solicitando que se declare a la sociedad Leasing Colmena S.A., en calidad de tomador, asegurada y beneficiaria del seguro contratado, responsable de las prestaciones prometidas en el contrato de seguro.

- De forma alternativa el demandante solicitó se reconocieran los perjuicios causados por los actos y omisiones de la sociedad Leasing Colmena S.A., relacionados con la perdida de la máquina retroexcavadora, el abuso de la posición dominante al contratar el seguro sin poder, el incumplimiento de la obligación de entregar el bien objeto del contrato de leasing y por ultimo alegó la ineficacia contractual en la medida que el bien objeto del contrato de leasing no existía al momento de ejercerse la opción de compra.

- $\quad$ En consecuencia, el demandante solicitó se condenara a la demanda a pagar la suma que se determinara como valor de la retroexcavadora hurtada, junto con el lucro cesante.

\section{ii. Problema Juridico}

¿Quién y con qué finalidad puede suscribir un contrato de seguro sobre las cosas objeto del contrato de leasing? 


\section{iii. Reseña de los Fallos de instancia}

Fallo de primera instancia: Se declararon fundadas las excepciones de mérito propuestas por la demandada y la aseguradora llamada en garantía, y se negaron las pretensiones del demandante.

- $\quad$ Fallo de segunda instancia: Se confirmó el fallo de primera instancia.

\section{iv. Fundamentos del fallo de segunda instancia}

El Tribunal confirmó la decisión adoptada en primera instancia indicando siguiente:

En cuanto a la contratación del seguro por parte de la sociedad demandada sin que esta tuviera poder del locatario para tal efecto, se consideró que tal circunstancia no configura un abuso de posición dominante en la medida que el contrato de leasing financiero establecía la obligación para el locatario de contratar dichos seguros, facultando al arrendador demandado para que ante la omisión por parte del locatario pudiera adquirir los mismos. De esta forma, consideró que ninguna de las pretensiones derivadas de la contratación del seguro por parte del arrendador podía prosperar.

Respecto a la entrega del bien objeto del contrato de leasing, el Tribunal consideró que la entrega del bien si se produjo y por tanto no existió incumplimiento de esta obligación por parte del arrendador. Sobre el particular el Tribunal indico que si la entrega del bien no se hubiere producido el contrato no se hubiera podido ejecutar y el locatario no hubiera tenido la posibilidad de ejercer la opción de compra sobre el bien como en efecto lo hizo.

- $\quad$ En cuanto a la ineficacia del contrato de leasing el Tribunal indicó que no era aplicable al caso en la medida que la opción de compra se ejecutó aun a sabiendas de la desaparición del bien. Adicionalmente indica que la opción de compra fue ejercida como una manera de responder al arrendador por el objeto del contrato de leasing.

Respecto al contrato de seguro adquirido por la arrendadora, el Tribunal se limitó a analizar si la demandada se encontraba facultada para adquirir el mismo. Sin embargo, no se analizó la existencia de un interés asegurable por parte del locatario y si eventualmente dicho interés se encontraba amparado con la póliza de seguro, pues en la medida que la arrendadora era quien ostentaba la calidad de tomador, asegurado y beneficiario en la póliza de seguro, era la única que tenía derecho al importe del seguro.

\section{v. Recurso de Casación}

El recurso de casación fue interpuesto por el demandante, Señor Roberto Buitrago Dueñas, quien alega la vulneración de los arts. 76, 830, 831, 846, 863, 897, 898, 918, 929, 981, 1038 a 1040, 1042, 1044, 1045, 1083, 1084 y 1101 del Código de Comercio, $63,1496,1498,1501,1502,1505,1506,1517,1524,1543,1602$ a 1604. 1613, 1616, 1618 a 1624, 1870, 1876 y 2005 del Código Civil, 187, 254 y 285 del Código de Procedimiento Civil, y los Decretos 2179 de 1992, 384 y 663 de 1993. 
El recurrente manifiesta como primer cargo que el Tribunal incurrió en errores de hecho al omitir el valor y los efectos de los certificados de seguro aportados, los recibos de pago de la prima que demuestran que el demandado fue quien pago la misma, la confesión del demandado en cuanto a que el demandante es asegurado en la póliza, la confesión de la aseguradora en cuanto a que la ley faculta a la demandada para asegurar sus bienes y le permite tomar el seguro por cuenta de otro.

En la demostración de los errores el recurrente considera que si el Tribunal hubiera tenido en cuenta las pruebas por el indicadas, hubiera podido concluir, entre otras, (i) que existía un seguro por cuenta en el que el beneficio del mismo no es exclusivo de la arrendadora; (ii) que por ser el contrato de arrendamiento un contrato de adhesión, imponía aplicar el principio pro-consumidor y en tal medida la arrendadora debía entregar al locatario la indemnización que percibiera con ocasión del seguro; (iii) la falta de interés asegurable de la arrendadora una vez transfirió al demandante el bien objeto del contrato; (iv) el incumplimiento de las obligaciones derivadas del contrato de leasing; (v) el desequilibrio contractual; y (vi) la inobservancia de las normas que regulan la actividad financiera y aseguradora.

En el segundo cargo el recurrente indica que el Tribunal otorgo a los contratos objeto de la demanda un valor probatorio del cual carecían y en tal medida incurrió un error de derecho ${ }^{1}$ que lo llevo a desestimar las pretensiones de la demanda.

\section{vi. Consideraciones de la Corte}

La Corte comienza indicando que lo expresado por el recurrente en el segundo cargo, son cuestiones típicamente de hecho en la medida que se relacionan con el entendimiento, cumplimiento o incumplimiento de un contrato. En tal sentido, el estudio de los cargos propuestos por el recurrente en el cargo primero, se estudiará bajo la perspectiva de la comisión de errores de hecho ${ }^{2}$.

Inicia la Corte por establecer que las pretensiones principales se derivan de la condición que ostenta la arrendadora como tomadora, asegurada y beneficiaria del contrato de seguro, dirigiendo la acusación a demostrar que el mismo fue tomado por cuenta del demandante y por tanto éste es quien tiene derecho a la indemnización correspondiente.

\footnotetext{
1 Respecto al error de derecho, el tratadista Hernando Morales indicó que "en el error de derecho la prueba se estima, pero se le niega el valor que la ley le asigna o se le da el valor que la ley le niega. En este tipo de error, en primer lugar, el juzgador viola las disposiciones legales sobre valoración probatoria, y esta infracción lo lleva a infringir normas de derecho sustancial". (MoRALEs M., 1963, p. 218).

2 Respecto a los errores de hecho se ha indicado que "el error de hecho en materia de Casación es una creencia o noción equivocada del juez frente a los hechos revelados por la prueba, la demanda o la contestación, que se percibe al instante y que entraña la violación indirecta de la ley. Se refiere al examen materia de la prueba o aspecto exclusivamente factico o probatorio; por lo tanto, se concibe como falsa noción del hecho del cual la prueba da cuenta o creencia equivocada de que ha sucedido un hecho, cuando no es así, o de que no ha ocurrido, estando plenamente acreditado en el proceso. El error de hecho tiene lugar cuando el sentenciador no ve la prueba que obra en el expediente, o supone la que no existe. En este caso el error también debe ser manifiesto, evidente y trascendente". (Tolosa Villabona, 2008, pp. 371-372).
} 
Sobre el particular, la Corte estableció que el Tribunal incurrió en un error de hecho en la medida que concluyó que la demandada era la única que tenía derecho al importe del seguro, debido a que era quien ostentaba las calidades de tomador, asegurado y beneficiario, sin percatarse que en las condiciones generales de la póliza en cuestión, se contemplaba el aseguramiento tanto de los intereses propios del tomador, esto es la demandada en calidad de arrendataria, como de los locatarios de los bienes objeto del contrato de leasing. En igual sentido, estableció que el error de hecho se sustenta en que tampoco se tuvieron en cuenta las pruebas aportadas entre estas el certificado de seguro, documento donde se nombró como asegurado por las contingencias al demandante.

No obstante los errores evidenciados por la Corte, ésta indica que los mismos carecen de trascendencia para variar la decisión adoptada por el Tribunal en la medida que al indicarse que el demandante tenía derecho a la prestación asegurada, el cumplimiento de tal obligación correspondía a la aseguradora una vez desvirtuadas las razones de la objeción por ésta formulada. Sin embargo, en la medida que la demanda se dirigió únicamente contra la sociedad Leasing Colmena S.A., la Corte se ve imposibilitada para estudiar la responsabilidad de la aseguradora en la medida que el llamamiento en garantía que se efectuó contra ésta, no permite dicho análisis pues el mismo solo es posible en la eventualidad que exista una condena contra el llamante o demandado.

\section{B. Evaluación crítica}

Respecto a la decisión adoptada por la Corte, en efecto se incurre en un error de hecho por parte del Tribunal en la medida que este no valoró de forma integral las pruebas y, por tanto, no evidenció que, en las condiciones de cobertura del contrato de seguro, se contempló tanto la cobertura del interés asegurable que ostenta el arrendador, como la cobertura del interés en cabeza del locatario.

Ahora bien, el hecho que el demandante hubiere equivocado su acción y no la hubiera dirigido contra la aseguradora, persona que en el marco del contrato de seguro es quien asume los riesgos y por tanto es el obligado a responder por la prestación asegurada, no impide que se efectué un análisis que permita entender quienes, en el marco de la ejecución de los contratos de leasing, ostentan algún interés que resulte asegurable.

En tal sentido, se debe tener en cuenta que conforme a lo establecido en el artículo 1083 del Código de Comercio, el interés asegurable lo ostenta toda persona cuyo patrimonio se pueda ver afectado directa o indirectamente por la materialización del riesgo, por lo que aplicando esta definición a la situación jurídica que se crea con ocasión de la celebración de un contrato de leasing, se evidencia que las dos partes del contrato tienen interés respecto a la cosa objeto del contrato de leasing.

Por una parte, la existencia del interés asegurable en cabeza del arrendador se deriva de su condición de titular del derecho de dominio sobre el bien objeto del leasing, de forma que la materialización de un eventual riesgo implicaría una clara afectación patrimonial respecto de la cual el contrato de seguro tiene la capacidad de operar. 
Lo anterior no implica que sobre el mismo no subsistan otra serie de intereses susceptibles de ser asegurados ${ }^{3}$. Es así como en el presente caso la cobertura del contrato de seguro no se encontraba limitada al perjuicio patrimonial que eventualmente sufriera el arrendatario como titular del derecho de dominio sobre la cosa objeto del seguro y por ende del contrato de leasing, sino que por el contrario y conforme se detallaba en las condiciones generales del contrato de seguro, la cobertura se extendía al cubrimiento del interés que el locatario tuviera con ocasión del contrato de leasing.

Quiere esto decir que, ante la materialización del riesgo y habiendo la aseguradora asumido la cobertura de los dos intereses presentes en el contrato de leasing, esto es el interés que tiene el arrendador sobre el bien con ocasión a la titularidad del derecho de dominio y el interés que tiene el locatario respecto a la amortización del valor del bien, la posibilidad de ejercer la opción de compra y la obligación que se generaría ante el no ejercicio de la misma y la consecuente restitución del bien arrendado, la aseguradora debería haber evaluado cual fue el perjuicio o la afectación patrimonial que se generó al arrendador y al locatario con ocasión de la materialización de un riesgo como resulta ser el hurto del bien asegurado, esto teniendo en cuenta los limites asegurados y establecidos en el contrato de seguro, así como el hecho que tanto arrendador como locatario ostentaban conjuntamente la calidad de asegurados y beneficiarios de la prestación asegurada.

Así, teniendo en cuenta la finalidad y el propósito de los contratos de leasing, se puede concluir que, en estos casos, la contratación del seguro no se puede limitar a ninguna de las formas contempladas en la normatividad colombiana, esto es, la contratación por cuenta propia o ajena, pues se pueden ver involucradas las dos formas en la medida que sobre el bien existen interés de ambas partes del contrato de leasing. Sobre el particular se ha indicado:

"Si el interés que constituye el objeto del contrato, se afirma en la persona contra-
yente, el seguro es por cuenta propia; si por el contrario ello sucede en la persona de
un tercero, el seguro es por cuenta ajena. (...) Se observa de la norma transcrita -art.
$1042-$ que se contempla la posibilidad de que el tomador del seguro tenga interés ase-
gurable lo que determina que en estricto sentido no puede hablarse en esta hipótesis
de la existencia de seguro por cuenta, dado que si el mismo tomador está cubriendo,
así sea en parte, un interés propio, en lo que con el mismo concierne no existirá seguro
por cuenta de un tercero, de ahí que se tipifique la modalidad mixta que se advierte"
(LoPez BLANCO, 2014, pp. 211-212).

Esta mixtura de que trata el autor es perfectamente aplicable a la suscripción de seguros respecto a bienes que son objeto del contrato de leasing, pues como se ha indicado, sobre estos subsisten intereses de ambas partes sin que exista ningún tipo de prohibición para que se utilice una figura mixta en la suscripción de estos seguros, es decir, que el seguro se suscriba por cuenta propia trasladando así los riesgos propios

\footnotetext{
3 El art. 1084 del Código de Comercio, establece que "Sobre una misma cosa podrán concurrir distintos intereses, todos los cuales son asegurables, simultánea o sucesivamente, hasta por el valor de cada uno de ellos. Pero la indemnización, en caso de producirse el hecho que la origine, no podrá exceder del valor total de la cosa en el momento del siniestro. Su distribución entre los interesados se hará teniendo en cuenta el principio consignado en el art. 1089”.
} 
que sobre los bienes objeto del contrato de leasing tenga una persona, y que simultáneamente se trasladen los riesgos de un tercero sobre el mismo objeto.

\section{CORTE SUPREMA DE JUSTICIA -SALA DE CASACIÓN CIVIL}

Fecha: 2 de diciembre de 2011, discutida y aprobada en sala el 22 de noviembre de 2011. Expediente: 11001-3103-035-2000-00899-01.

Magistrado ponente: William Namén.

\section{A. Reseña}

\section{i. Hechos}

- $\quad$ El 7 de octubre de 1998 un vehículo de servicio público de propiedad de Leasing de Occidente S.A., afiliado a la empresa Pereirana de Transportes Ltda, conducido por José Vehyman Granados, atropelló a los Señores Nicolás Dalmiro Alzate y Jairo Antonio Salazar quienes se movilizaban en una motocicleta.

Como consecuencia del accidente de tránsito fallecieron los Señores Nicolás Dalmiro Alzate y Jairo Antonio Salazar.

- $\quad$ Los Señores Elvira Lezcano, Gilberto de Jesús Alzate y Luz Elena Alzate Lezcano, ésta última en su nombre y el de sus hijos Johan Alexander y Jonathan Stiven Salazar Alzate, presentaron demanda ordinaria contra la sociedad Leasing de Occidente S.A., Pereirana de Transportes Limitada y José Vehyman Granados Marín, con la finalidad de que se declarará la responsabilidad civil, extracontractual y solidaria de los demandados por los daños materiales y morales causados con la muerte de Nicolás Dalmiro Alzate Lezcano y Jairo Antonio Salazar.

La demandada Leasing de Occidente presentó excepciones previas y propuso las denominadas, falta de legitimación en la causa por pasiva, inexistencia de responsabilidad, prescripción, culpa de la víctima, culpa o responsabilidad de terceros, fuerza mayor y caso fortuito.

- $\quad$ Mediante auto del 8 de abril de 2005, el Juez de conocimiento acepto el desistimiento frente a la sociedad Pereirana de Transportes Ltda y José Vehyman Granados Marín.

\section{ii. Problema Juridico}

¿Bajo la teoría de la responsabilidad civil por el hecho de las cosas y el ejercicio de actividades peligrosas, al ser titular del derecho de dominio la compañía de leasing tiene interés asegurable respecto a los riesgos de responsabilidad civil extracontractual que se puedan configurar o sean causados por los bienes objeto del leasing? 


\section{iii. Reseña de los Fallos de instancia}

- $\quad$ Fallo de primera instancia: Se negaron las pretensiones y se condenó en costas a la parte demandante.

- $\quad$ Fallo de segunda instancia: Resolvió el recurso de apelación formulado por los demandantes confirmando la sentencia recurrida.

\section{iv. Fundamentos del fallo de segunda instancia}

El tribunal confirmó la sentencia de primera instancia haciendo referencia a los siguientes argumentos:

- $\quad$ Indicó que, respecto a la responsabilidad civil derivada por el ejercicio de actividades peligrosas, por su naturaleza dicha responsabilidad lleva implícita la culpa en caso de accidente, la cual se hace extensiva al dueño y empresario de la cosa con la que se causa el perjuicio, esto en la medida que se presume como el guardián de las cosas inanimadas.

- $\quad$ El hecho que se presuma que el titular del derecho de dominio es quien debe velar por la guarda y cuidado de las cosas, no implica que en todos los casos el propietario sea el guardián de las mismas o efectúe su manejo material y físico, por lo que tal presunción puede ser objeto de prueba en contrario.

- $\quad$ Respecto al servicio de transporte, se indica que es el prestador del servicio quien ostenta el calificativo de guardián de la cosa y no necesariamente el dueño de la misma.

El Tribunal establece sobre la base del material probatorio, que Leasing de Occidente S.A., es la dueña de la cosa con la cual se causó el perjuicio, sin embargo dicha cosa fue entregada a la empresa Transportes Pereira S.A., en virtud del contrato de leasing, de forma que la primera carece de dirección y control sobre la misma, desvirtuando así la presunción de guardián derivada de su condición de titular del derecho de dominio, por cuanto no está llamada a responder por los daños causados a los demandantes.

\section{v. Recurso de Casación}

El recurso de casación fue interpuesto por los demandantes, quienes alegan la violación directa por inaplicación de los arts. $4^{\circ}$ del Código de Procedimiento Civil, 2341, 2353 inciso primero, 2356 del Código Civil y $1^{\circ}$ de la Ley $\mathrm{N}^{\circ} 95$ de 1890, así como la indebida aplicación del artículo $5^{\circ}$ del C. de P.C.

El primer cargo se soporta en una supuesta violación al derecho a la igualdad, el debido proceso, un error de derecho materializado en la inaplicación de los arts. 2341, $2353 \mathrm{y}$ 2356 del Código Civil, y una indebida aplicación del artículo $5^{\circ}$ del C. de P.C., toda vez que si bien el mismo autoriza al juzgado a aplicar la jurisprudencia ante la ausencia de normas, el tribunal no aplicó las normas y creo una nueva clase de victimas del daño ori- 
ginado por bienes objeto de leasing, adicionando un eximente de responsabilidad como lo es la causación de daños con bienes dados en leasing.

En el segundo cargo el recurrente alega un error de hecho en la aplicación de la prueba toda vez que no valora de forma integral el material probatorio, limitándose a valorar una sola prueba como lo es la que demuestra la propiedad del agente generador del daño, obviando pronunciarse sobre otras pruebas y sobre los hechos que originaron la demanda.

\section{vi. Consideraciones de la Corte}

En primer lugar, la Corte indica que la formulación de los cargos propuesta por el recurrente, carece de claridad y precisión, situación que reitera es necesaria dada la naturaleza extraordinaria de la casación.

Aclara entonces que la violación directa como consecuencia de la inaplicación, aplicación indebida o interpretación errónea de la ley, difiere de la indirecta por error factico o de derecho probatorio. Sobre el error de hecho destaca que este recae sobre la contemplación material, física u objetiva de la prueba, sea por ignorar u omitir la existente, alterarla o distorsionarla con su adición o distorsión, o bien por figurar o imaginar la inexistente. Respecto al error de derecho sintetiza que el mismo se predica de la contemplación jurídica de la prueba y se produce cuando el fallador desconoce las reglas inherentes a su producción o eficacia legal, sea por negarle el mérito probatorio dado por la ley o por otorgarle uno del cual carece, lo cual exige enunciar los preceptos probatorios vulnerados.

Manifiesta que en la casación los cargos operantes son los que se refieren a las bases del fallo recurrido, de forma que cuando los mismo no se fundamentan de tal forma son inoperantes, pues el recurrente no puede aducir argumentos en que no se apoya el fallo recurrido, ni limitarse a divergir, criticar, censurar o ensayar, o plantear una perspectiva diferente, pues la tarea de la Corte no es revisar una vez más el asunto litigado, sino establecer si el falo adoptado se encuentra conforme al derecho objetivo.

Una vez criticada la estructura de los argumentos y en general del recurso propuesto por el recurrente, indica que la conducción de automotores ha sido calificada por la jurisprudencia como una actividad peligrosa ${ }^{4}$, que aunque licita implica riesgos de tal naturaleza que hacen inminente la ocurrencia de daños. Así, indica que la responsabilidad civil por daños causados en accidentes de tránsito se enmarcan dentro del régimen de las actividades peligrosas previstas en el artículo 2356 del Código Civil, de forma que conforme a la jurisprudencia de la sala basta acreditar el ejercicio de la actividad peligrosa, el daño y la relación de causalidad entre estas para estructurar la responsabilidad civil, de forma que el agente solo puede exonerarse probando la

\footnotetext{
4 En Sentencia del 23 de junio de 2015 Exp. N ${ }^{\circ}$ 70215-31-89-001-2008-00156-01 la Sala de Casación Civil de la Corte Suprema de Justicia indica respecto a las actividades peligros y la responsabilidad civil que se deriva de las mismas, que "los presupuestos estructurales de la responsabilidad civil son la existencia de un hecho u omisión, un daño y la relación de causalidad entre los dos anteriores. El art. 2356 del Código Civil gobierna la que se deriva de las actividades peligrosas, y armonizado con el 2347 ibídem permite predicar que es directa, tanto la del autor físico como la del guardián de la cosa".
} 
existencia de un elemento extraño, esto es la fuerza mayor, el caso fortuito o la culpa exclusiva de la víctima, caso en el cual se rompe el nexo causal y por tanto se excluye la autoría.

De esta forma indica la Corte que se debe indagar quien es el responsable de la actividad peligrosa, pues el responsable por el hecho de las cosas inanimadas es su guardián, es decir quien tiene sobre ellas poder de mando, dirección y control, por lo que si bien se puede presumir del propietario tal calidad de guardián, no es cierto que la condición ineludible, por lo que puede ser objeto de prueba en contrario, por ejemplo demostrando la transferencia de la tenencia bajo un título jurídico como resulta ser el arrendamiento, comodato, o el despojo inculpable como resulta ser el hurto de la cosa.

Por lo tanto, la responsabilidad que se analiza recae en el guardián material de la actividad causante del daño, es decir la persona que al momento del accidente tiene sobre el instrumento generador del daño un poder efectivo e independiente de dirección, gobierno o control, sea o no el dueño, y siempre que no se vea imposibilitado para ejercer ese poder.

En tal sentido, la presunción de responsabilidad del dueño por el hecho de las cosas inanimadas, proveniente de la calidad de guardián que se presume sobre las mismas, está condicionada al hecho que el propietario se hubiera desprendido voluntariamente de la tenencia o si, contra su voluntad y sin mediar culpa alguna de su parte, perdió dicha tenencia, de forma que la responsabilidad se desvanecería.

Ahora bien, respecto a la responsabilidad que se deriva por el ejercicio de una actividad peligrosa, debe tenerse en cuenta que, en el ordenamiento jurídico colombiano, la responsabilidad que nace del ejercicio de este tipo de actividades radica no en la guarda de la cosa sino en el ejercicio mismo de la actividad. En tal sentido, este tipo de responsabilidad puede comportar el uso de una cosa inanimada respecto de la que inicialmente se reputa una responsabilidad civil por el hecho de las cosas, no obstante, esta mutará en el momento en que dicha cosa sea utilizada en el ejercicio de una actividad peligrosa.

Conforme a lo anterior, determina la Corte que el juzgador en el caso concreto pudo determinar y apreciar conforme a los elementos probatorios, que el daño se produjo dentro del ejercicio de una actividad peligrosa, de forma que la presunción de culpabilidad establecida respecto al propietario, fue desvirtuada en la medida que él no ejerce dicha actividad, razón por la cual indicó que el Tribunal no incurrió en error probatorio toda vez que habiendo determinado que Leasing de Occidente no estaba llamada a responder por los daños, no era necesario evaluar los demás presupuestos de responsabilidad.

\section{B. Evaluación crítica}

Es claro que la compañía de leasing ostenta un interés asegurable respecto a los riesgos a los que se encuentra expuesto la cosa o los bienes que son objeto de los contratos de leasing. Sin embargo, tal situación merece un análisis independiente respecto a los riesgos que en el plano de la responsabilidad civil por el hecho de las cosas o el 
ejercicio de actividades peligrosas se refiere y en lo que al interés de asegurar este tipo de riesgos respecta.

Así, evidenciamos que si bien estamos frente a una clara situación en la que un seguro todo riesgo contratado para amparar los bienes o cosas objeto del contrato de leasing, puede tener un amparo de responsabilidad civil extracontractual que cubra los perjuicios que cause el asegurado, entiéndase este tanto la leasing como el locatario de los bienes pues juntos tienen un interés asegurable sobre el particular, es necesario determinar el alcance de dicha cobertura de forma que se pueda determinar quién es el sujeto que se encuentra expuesto a la comisión de actos que eventualmente impliquen la necesidad de reparar el eventual daño que se cause por el uso de los bienes o cosas objeto del contrato de leasing y la activación de la correspondiente cobertura del seguro.

Conforme a las distintas formas de responsabilidad contenida en el Código Civil, se ha indicado que

"El referido título puede dividirse en tres grupos: (i) el primero, conformado por los arts. 2341 y 2345 que contiene los principios generales de la responsabilidad civil por los delitos y las culpas generados por el hecho propio; (ii) el segundo, constituido por los arts. 2346, 2353, 2354, 2355, y 2356, concerniente a la responsabilidad por el hecho de las cosas animadas o inanimadas" (Sentencia, 2012).

No obstante la anterior clasificación, debe tenerse en cuenta que es gracias a la jurisprudencia que a partir de lo establecido en el artículo 2356 se ha creado una nueva categoría en alusión a la responsabilidad que se deriva por el desempeño o desarrollo de actividades peligrosas, definidas éstas como "cosas o energías, o actividades con un alto riesgo de generar daños a terceros, tales como las que se relacionan con vehículos, ferrocarriles, energía eléctrica, atómica, etc.” (Velásquez Posada, 2009, p. 88).

Ahora bien, en lo que respecta a la posibilidad de establecer cuál de las partes de un contrato de leasing es quien ostenta un riesgo de responsabilidad susceptible de ser amparado por un contrato de seguro, es necesario aclarar que el contrato de leasing tiene por objeto la entrega al Locatario de un determinado objeto o cosa que en todo caso es propiedad de la compañía de leasing, no obstante dicha entrega tiene por finalidad que el Locatario realice el uso y goce del bien a cambio del pago periódico de una suma de dinero por un término de tiempo determinado, momento en el cual nace para el Locatario el derecho a la denominada opción de compra.

Como se observa aunque la compañía de leasing mantenga la titularidad del bien objeto del contrato, escapa a su competencia el dominio y control sobre el mismo, pues el locatario es quien en virtud del contrato de leasing, determina la forma de uso del bien, por lo que si bien en un principio podría pensarse en aplicar la teoría de la responsabilidad por el hecho de las cosas y aplicar la presunción de responsabilidad que subsiste en cabeza del propietario, debe tenerse en cuenta que al ser el Locatario quien ostenta la responsabilidad de custodiar el bien entregado en arrendamiento, es de suyo la responsabilidad que se deriva por la ejecución de dicha actividad, relevando en tal caso a la compañía quien solo en caso que el Locatario se abstenga de ejercer la opción de compra y por tanto devuelva el correspondiente bien, tendrá como 
obligación la guarda de la cosa, momento en el cual podría llegar a configurarse una eventual responsabilidad por el hecho de las cosas, debiendo en tal caso prever que la cobertura del seguro todo riesgo contemple la cobertura de la eventual responsabilidad civil que en virtud de tal circunstancia se pudiera llegar a materializar, debiendo en tal caso contemplar y diferenciar entre los riesgos que se pueden materializar en cabeza del Locatario y los que se encuentren en cabeza de la compañía de Leasing, la cual no tendría interés asegurable respecto a la cobertura de responsabilidad civil extracontractual que se derive por el ejercicio de actividades peligrosas.

Teniendo en cuenta lo anterior, al Locatario es quien le asiste el interés de contratar un seguro que le dé cobertura a este tipo de situaciones, las cuales puede que no se encuentren cubiertas en el seguro todo riesgo que contrata la compañía de Leasing por cuenta de sus clientes (Locatarios).

\section{CONSEJO DE ESTADO -SALA DE LO CONTENCIOSO ADMINISTRATIVO- SECCIÓN TERCERA, SUBSECCIÓN A.}

Fecha: 4 de noviembre de 2015.

Expediente: 25000232600019980248501 (33.571).

Consejero Ponente: Hernán Andrade Rincón.

\section{A. Reseña}

\section{i. Hechos}

- $\quad$ El 20 de septiembre de 1996, el grupo guerrillero ELN incineró un automotor de propiedad de la señora Elsa Silva Fernández quedando totalmente destruido.

- $\quad$ Al día siguiente se formuló reclamación contra la compañía Aseguradora Colseguros S.A., con fundamento en la cobertura contemplada en la póliza No. 09222-006663, vigente para la época de los hechos.

La compañía Aseguradora Colseguros S.A., informó que dicha póliza excluía de forma expresa los siniestros cubiertos por el seguro de peajes, y que los actos de grupos subversivos estaban cubiertos por una póliza tomada por el Ministerio de Transporte con la Previsora S.A.

- La demandante formuló reclamación ante Previsora S.A, quien negó el pago de la indemnización al considerar que existían incongruencias entre la declaración de importación y el registro de importación del vehículo, así como otro tipo de inconsistencias frente a la identificación del automotor, lo que se configuraba en una exclusión de la póliza toda vez que se incurrió en la infracción administrativa de contrabando.

- $\quad$ La actora aportó a la Previsora S.A., pruebas de la importación del vehículo con las cuales pretendía desvirtuar las aseveraciones efectuadas por la compañía. 
- $\quad$ Para la época de los hechos el vehículo hacia parte de un contrato de leasing suscrito con la sociedad Progreso Leasing S.A., quien ante la ocurrencia del siniestro exigió el cumplimiento del contrato, ante lo cual la actora pago el saldo pendiente del contrato y ejecutó la opción de compra del mismo, haciéndose propietaria del automotor.

- $\quad$ La demanda inicialmente radicada por la accionante, pretendía se declarará una falla en el servicio por parte de la Previsora S.A., en tal sentido, fue remitida a por competencia a la jurisdicción ordinaria por considerarse que la controversia versaba sobre un presunto incumplimiento de un contrato de seguro celebrado entre el Ministerio de Transporte y la Previsora S.A.

- $\quad$ El Juzgado 10 Civil del Circuito de Bogotá, estimo que la discusión se enmarcaba en el cumplimiento de un contrato estatal a la luz de lo dispuesto en el artículo 75 de la Ley $N^{\circ} 80$ de 1993, razón por la que propuso conflicto negativo de competencia.

La sala Disciplinaria del Consejo Superior de la Judicatura, resolvió que el asunto debía ser remitido a la Jurisdicción de lo Contencioso Administrativo.

El 23 de agosto de 1999, la demanda fue admitida y se resolvió no vincular al Ministerio de Hacienda y Crédito Público, toda vez que la Previsora S.A., tiene una naturaleza de Empresa Industrial y Comercial del Estado dotada de personería jurídica y capacidad para comparecer directamente en el proceso.

- $\quad$ En auto del 3 de septiembre de 2003 el Tribunal a quo ordenó citar como litisconsorte necesario por pasiva a la Nación -Ministerio de Transporte y posteriormente en auto del 12 de diciembre de 2003 se vinculó al Instituto Nacional de Vías - INVIAS.

La Previsora S.A., contestó la demanda oponiéndose a las pretensiones para lo cual propuso las excepciones de ausencia de responsabilidad, ilegitimidad en la causa, falta de jurisdicción, inepta demanda y no comprender la demanda a todos los litisconsortes necesarios.

- $\quad$ El Ministerio de Transporte y el Instituto Nacional de Vías -INVIAS, contestaron la demanda proponiendo excepciones como la falta de legitimación en la causa por pasiva e inexistencia de la obligación.

\section{ii. Problema Jurídico}

¿El contrato de leasing implica para el locatario la posibilidad de subrogarse en los derechos del leasing de forma que en su calidad podría efectuar la reclamación y percibir la indemnización del seguro de daños?

\section{iii. Reseña de los Fallos}

- $\quad$ Fallo de primera instancia: El Tribunal resolvió negar las pretensiones formuladas en la demanda. 
- $\quad$ Apelación: La el Consejo de Estado, en Sala de lo Contencioso Administrativo, Sección Tercera, confirmó la sentencia proferida por el Tribunal.

\section{iv. Sentencia de Primera Instancia}

El La Sección Tercera del Tribunal Administrativo de Cundinamarca, resolvió negar las pretensiones de la demanda con fundamento en los siguientes argumentos:

- $\quad$ Indicó que la demandante no ostentaba la calidad de beneficiaria de la Póliza de Seguro, toda vez que para la fecha de los hechos que se describen como siniestro, si bien tenía el uso y goce del vehículo asegurado, no era la propietaria del mismo por lo que todavía no se había hecho efectiva la opción de compra contemplada en el Contrato de Leasing.

- $\quad$ La transmisión del derecho de dominio en razón al ejercicio de la opción de compra, no implica la subrogación del adquirente en los derechos que como acreedor tuviera el antiguo propietario, quien es el que tiene derecho al reconocimiento y pago de la indemnización con fundamento en la Póliza de Seguro objeto de la disputa.

Consideró que, al no ser la beneficiaria de la Póliza de seguro, no existía ningún daño antijurídico que se desprendiera del no pago de la correspondiente indemnización por parte de la Aseguradora.

\section{v. Fundamentos de la Apelación}

La demandante interpuso de forma oportuna el recurso de apelación en contra de la sentencia de primera instancia, solicitando la revocatoria y se acogieran favorablemente las pretensiones de la demanda sobre los siguientes argumentos:

- Se refirió a la póliza contratada por el Ministerio de Hacienda y Crédito Público, la cual amparaba a los vehículos de servicio público municipal e intermunicipal en el territorio nacional frente a actos provenientes de huelgas, amotinamientos, conmociones civiles y/o terrorismo.

- Indicó la demandante que el siniestro reclamado se encontraba amparado por la cobertura de la referida póliza y que, al establecerse como beneficiarios a los terceros indeterminados, el amparo cobija no solo a los propietarios sino a cualquier persona que resulte lesionada por la destrucción o los daños sufridos por el vehículo de servicio público.

- $\quad$ Considera la demandante que es errada la apreciación del tribunal en considerar como único beneficiario de la póliza a la Leasing por ostentar esta la calidad de propietaria del vehículo asegurado, pues la póliza no establece tal condición para resultar ser beneficiaria de la misma, sino que se refiere a beneficiarios indeterminados.

- $\quad$ Frente a los argumentos de la Previsora, se indicó que es esta quien legalmente tiene la carga de la prueba, y que con las pruebas documentales aportadas al 
proceso se desvirtuaron los argumentos que respecto a la importación y la legalidad de la matrícula del vehículo se esgrimieron.

\section{vi. Consideraciones del Consejo de Estado}

El Consejo de Estado inicia su análisis determinando si los fundamentos facticos que soportan la demanda instaurada tienen origen en un contrato estatal o si por el contrario son producto de un hecho, omisión, operación administrativa o de la ocupación temporal o permanente de un inmueble como consecuencia de trabajos públicos o de cualquier otra causa.

Manifiesta que la demanda se fundamentó en una supuesta falla en el servicio ${ }^{5}$ por parte de la Previsora, quien con fundamento en unos argumentos que contemplaban la comisión de la infracción administrativa de contrabando, se había negado a efectuar el pago de la correspondiente indemnización por la materialización del riesgo cubierto por la póliza suscrita por el Ministerio de Hacienda.

Así, considera el Consejo de Estado que la acción que ejerció la demandante es una acción contractual que pretende declarar el incumplimiento de un contrato de seguro, y no como se indica en la demanda una falla en el servicio por el hecho de negar el correspondiente pago de la indemnización. Sin embargo, considera que es necesario interpretar la pretensión de la demandante razón por la cual aclara la situación y continua con el correspondiente estudio.

De esta forma, indica que lo que se pretende con el recurso de apelación interpuesto por el demandante es la revocatoria de la sentencia de primera instancia de forma que se indique que los daños sufridos por la demandante estaban amparados por la póliza tomada por el Ministerio de Hacienda y Crédito Público pues en la misma se indican como beneficiarios a terceros indeterminados y no se configuró la causal de exclusión invocada por la Aseguradora en la medida que no se demostró que el automotor objeto del daño ingresara al país de maneja ilegal o que su matrícula fuera fraudulenta, esto en la medida que probatoriamente estos argumentos fueron desvirtuados.

De esta forma inicia la Sala haciendo un estudio de la legitimación en la causa por activa para el caso concreto, en este sentido indica que existe una diferencia entre la legitimación del hecho y la legitimación material en la causa, indicando que la primera se refiere a la relación procesal entre el demandante y el demandado, es decir, se trata de una relación jurídica que nace de la conducta demandada, de forma que quien inicia la acción pretende endilgar la conducta, sea esta una acción u omisión al demandado

\footnotetext{
5 Respecto a la falla en el servicio se ha establecido que "la falla en el servicio corresponde al régimen de responsabilidad subjetiva, donde predomina la culpa de la administración por extralimitación de funciones, retardo en el cumplimiento de obligaciones, obligaciones cumplidas de forma tardía o defectuosa, o por el incumplimiento de obligaciones a cargo del Estado. Son entonces acciones u omisiones que se predican de la administración y que, en su funcionamiento, resultan en cualquiera de las irregularidades generadoras de daños imputables al estado, régimen tradicional en constante evolución, al margen de la responsabilidad objetiva reconocida positivamente en norma superior, consignada en el art. 90 de la Constitución Política". (Ruiz OrJuela, 2010, p. 2).
} 
quien se encuentra legitimado de hecho y por pasiva una vez sea notificado del auto admisorio de la demanda. Por otra parte, indica que la legitimación material supone la conexión entre las partes y los hechos y/o derechos constitutivos del litigio, bien porque resultaron perjudicadas, bien porque dieron lugar a la producción del daño.

En el caso en análisis, indica la Sala que el demandante alega su condición de beneficiaria de la póliza de seguro tomada por el Estado, situación que configura la legitimación de hecho en la causa por pasiva toda vez que la objeción frente al pago de la indemnización genera una afectación directa.

Conforme a los argumentos indicados por el Tribunal, en los que se manifiesta que la accionante no tenía la calidad de beneficiaria toda vez que para la fecha de los hechos, si bien tenía el uso y goce del vehículo objeto del daño, no ostentaba la calidad de propietaria o titular del derecho de dominio, pues fue solo hasta que decidió ejercer la opción contemplada en el contrato de Leasing que adquirió el mismo, la Sala considera que en la medida que el a quo únicamente se pronunció respecto a una de las pólizas indicadas en la demanda, esto es la No. 158161, y obvio pronunciarse respecto a la póliza No. 7-54778, tal situación habilita a la Sala para analizar los argumentos de la apelación.

En este orden de ideas, analiza las pruebas aportadas donde se evidencia el certificado de renovación de la póliza No. 7-54778, en la cual se aparece como tomador y asegurado el Ministerio de Hacienda y Crédito Público, mientras que en el espacio destinado al "beneficiario / Afianzado o contratista" se consignó "terceros indeterminados".

Analizado el contenido de la póliza, la Sala afirma que ante un siniestro de pérdida total daños, el beneficiario resulta ser exclusivamente el propietario del vehículo, pues es el derecho de dominio y el patrimonio del asegurado el que se ve menoscabado ante la ocurrencia del riesgo asegurado, por lo que indica que no es posible afirmar que cuando se hace referencia a terceros indeterminados como beneficiarios de la póliza, tal situación se extienda a persona distinta del propietario del automotor.

No obstante, la Sala reconoce que respecto del interés asegurable en los seguros de daños pueden existir múltiples intereses asegurados, como en este caso resulta ser el del tenedor del bien. Sin embargo y en atención el siniestro sobre el cual se configuró la reclamación, fue una pérdida total por daños, no obstante aclara que la póliza contemplaba el amparo de los daños por pérdida parcial y el lucro cesante, el legitimado para exigir el amparo reclamado es el propietario del bien, quien es quien sufre un menoscabo en su patrimonio como consecuencia de la materialización del riesgo (pérdida total por daños) y no al arrendatario o locatario, condición que ostentaba la demandante para la fecha de ocurrencia de los hechos.

Sumado a lo anterior, se indica que la tradición efectuada como consecuencia del ejercicio de la opción de compra contemplada en el contrato de Leasing, no incluyó una cesión de derechos con la finalidad de reclamar la indemnización debida a la luz del amparo conferido por la póliza No. 7-54778, por lo que la Sala indica que no puede entenderse que la compraventa realizada tuviera el alcance de transmitir un derecho distinto al de propiedad y en tal motivo confirma la sentencia apelada. 


\section{B. Evaluación crítica}

En concordancia con lo establecido por la Sala, debe indicarse que el hecho que en la póliza se indique que ostentará tal calidad los "terceros indeterminados", no quiere esto decir que cualquier persona tenga tal calidad y por tanto pueda exigir el pago de una indemnización, pues para tal efecto es necesario mirar la naturaleza del amparo que se pretende activar. Así las cosas, es claro que el demandante en esta ocasión equivoco su pretensión en la medida que el amparo bajo el cual fundamentó su reclamación, esto es la pérdida total por daños, exige la demostración de la calidad de propietario del bien respecto del cual se produjo el daño, pues es este quien como consecuencia de la perdida por los daños sufre la afectación patrimonial.

Empero, es necesario recalcar lo indicado por la Sala respecto a la posibilidad de que concurran distintos intereses asegurables como consecuencia de la materialización de un riesgo. En tal sentido, considero que la Sala obvio en su estudio hacer referencia al interés que tiene el locatario en la protección del bien entregado, pues respecto del contrato de leasing el locatario tiene la obligación de restituir el bien salvo que se haga uso de la opción de compra, independiente que se esté en un modelo de leasing operativo o el denominado leasing financiero, clasificación respecto a la cual se ha indicado que

"El leasing financiero o entrega de bienes, es un contrato en virtud del cual una compañía arrendadora, entrega a título de arrendamiento unos bienes, financiando su uso y goce a cambio del pago de cánones durante un plazo determinado, pactándose para el arrendatario la facultad de ejercer una opción de adquisición al final del período (entre el 1 y el 10\% del valor del activo). (...) Leasing operativo o de prestación de servicios, es un contrato en virtud del cual, una persona natural o jurídica, denominada la arrendadora, entrega a otra, llamada arrendataria, la tenencia de un bien para su uso y goce, a cambio del pago de un canon o renta periódico. En este caso la opción de compra, sólo se presenta excepcionalmente y de existir, es por el valor comercial del bien. En el financiero la vocación del bien es pasar al patrimonio del locatario, y en el operativo consiste en permanecer en poder del arrendador" (BAEnA TORO \& Hoyos WaLteros, 2012, pp. 83-88).

En este escenario, es claro que no solo al propietario del bien le asiste un interés asegurable respecto del bien entregado en leasing, pues si bien la destrucción del mismo implica un eventual menoscabo en su patrimonio, el locatario también se encuentra expuesto a un riesgo que se deriva de la obligación contractual consistente en efectuar la entrega del bien en caso de no ejecutarse la opción de compra contemplada en el contrato de leasing.

En tal situación, considero que no resulta acertada la posición respecto de la cual únicamente quien ostente la calidad de propietario ostenta la calidad de beneficiario de la indemnización producto de la materialización del riesgo de pérdida total, esto en razón a que se supone que es quien ostenta un único interés asegurable, obviando de esta forma que la materialización del riesgo indicado conlleva la imposibilidad del cumplimiento de la obligación contractual de restituir el bien, situación que configura un claro perjuicio para el locatario quien se vería abocado al pago de la totalidad de los cánones y el valor contemplado en la opción de compra, situación que en mi crite- 
rio constituye un interés asegurable legitimo sobre la cosa (en este caso el vehículo). Respecto al interés asegurable se ha indicado que:

\begin{abstract}
"es muy amplio el concepto de interés asegurable en los seguros de daños. Tiene interés asegurable toda persona cuyo patrimonio pueda resultar afectado, directa o indirectamente, por la realización de un riesgo" (C. de Co., art. 1083). Definición con la cual quedan cubiertos todos los supuestos de daño patrimonial: la lesión del interés económico sobre una cosa corporal o incorporal concreta, mueble o inmueble, llámese interés de dueño, de usufructuario, de comunero (seguros reales), o la lesión del patrimonio en su unidad financiera como conjunto y confrontación de los derechos y obligaciones, por eventual incremento del pasivo a cargo del asegurado (seguros patrimoniales), o la frustración, por el siniestro, de una seria y razonable expectativa de lucro (lucro cesante)" (J. EFrÉN, 1991, p. 74).
\end{abstract}

Ahora bien, se podría pensar que el pago de la indemnización por concepto de la pérdida total al locatario podría eventualmente constituir un enriquecimiento que rompería con la naturaleza indemnizatoria del contrato de seguro, no obstante no se debe olvidar que existe un contrato que obliga al locatario a la amortización del valor del bien, lo que quiere decir que no existe un crecimiento patrimonial o enriquecimiento por parte del Locatario, pues debe tenerse en cuenta que la destrucción de la cosa objeto del contrato de leasing no lo libera de sus obligaciones.

De esta forma, si bien no considero acertada la postura de la Sala en cuando a indicar que únicamente el propietario tiene interés respecto al vehículo, la sentencia no permite conocer la totalidad de las condiciones en las que se encuentra expedida la póliza, lo que permitiría hacer un estudio más completo respecto a cuales son los riesgos asumidos por la compañía de seguros, pues es legal y contractualmente posible que solo ampare los daños causados a los terceros propietarios de los bienes respecto de los que se configure una pérdida total por daños.

Un comentario aparte merece un aparte de la sentencia la Sala hace referencia al amparo de lucro cesante contenido en la póliza, sin embargo, no determina si los perjuicios causados como consecuencia de la materialización del riesgo, esto es la pérdida total del vehículo, pudieran haber sido obtenidos por el demandante si hubiera pretendido afectar este amparo. En mi criterio tal situación no es posible toda vez que lo pretendido por el demandante no hace referencia al lucro dejado de percibir como consecuencia de la imposibilidad de hacer uso del bien, sino a los perjuicios derivados de la mera destrucción de este, en donde insisto puede evidenciarse conforme a las obligaciones del contrato de leasing, si existe una afectación patrimonial que legitima al locatario a exigir o pretender el pago de la indemnización, más aun cuando esa situación no lo libera del cumplimiento de sus obligaciones contractuales.

\title{
4. CONCLUSIONES GENERALES
}

Como se evidencia en las evaluaciones críticas efectuadas en cada una de las sentencias analizadas, se puede concluir que si bien la teoría en lo que respecta a la existencia de múltiples intereses asegurables, particularmente en lo que respecta a los contratos de Leasing existe cierta confusión por parte de los locatarios en cuanto a los intereses que estos tienen respecto de los bienes objetos del leasing. 
Esta situación se ve empeorada por la mala suscripción que efectúan las compañías de seguro, quienes, ante el evidente desconocimiento de la existencia de múltiples intereses asegurables respecto de un bien, limitan la cobertura a la titularidad del dominio sobre los mismos, quedando desprotegidos los intereses de los locatarios, consumidores financieros que en muchos casos desconocen las particularidades propias de los contratos de seguro y de leasing.

El desconocimiento de los derechos por parte de los locatarios y la ausencia de una normatividad que obligue a las entidades financieras a procurar la protección de los intereses de estos, ha derivado en la suscripción de seguros que únicamente procuran por la protección de los intereses de estas entidades, quedando de esta forma desprotegido el consumidor financiero que desconoce las particularidades de este tipo de contratos y quien de buena fe cree haber asegurado los eventuales riesgos a los que está expuesto.

En tal sentido y si bien se ha avanzado en la creación de normas de protección al consumidor con la finalidad de salvaguardar sus derechos y procurar una mayor comprensión de los productos, derechos y obligaciones de los consumidores, respecto a instrumentos como el leasing se evidencia una ausencia de normatividad que impida la desprotección de los intereses que sobre los bienes objeto de estos contratos tienen los locatarios, por lo que se hace necesario efectuar una minuciosa lectura de las condiciones de estos contratos de seguro de forma que se pueda determinar si los riesgos de los locatarios al igual que los de la leasing, son objeto de cobertura o si por el contrario únicamente los son los de la leasing como titular del derecho de dominio sobre dichos bienes.

\section{REFERENCIAS BIBLIOGRÁFICAS}

Baena Toro, D., \& Hoyos Walteros, H. (2012). Conceptos Básicos Sistema Financiero Colombiano. Bogotá: Ecoe Ediciones.

J. Efrén, O. (1991). Teoría General del Seguro. Bogotá: Temis.

Lopez Blanco, H. F. (2014). Comentarios al Contrato de Seguros. Bogotá: Durpré Editores.

Morales M., H. (1963). Técnicas de Casación Civil. Bogotá: Ediciones Lerner.

Ruiz Orjuela, W. (2010). Responsabilidad del Estado y sus Regímenes. Bogotá: Ecoe Ediciones.

Sentencia, Exp. 2006-00094 (Corte Suprema de Justicia-Sala de Casación Civil 18 de Diciembre de 2012).

Tolosa Villabona, L. A. (2008). Teoría y Técnica de la Casación . Bogotá: Ediciones Doctrina y Ley Ltda.

Velásquez Posada, O. (2009). Responsabilidad Civil Extracontractual. Bogotá : Editorial Temis. 
